\title{
The Significance of Platelet Count in Short-Term Prognosis of Type B Acute Aortic Dissection Patients
}

\author{
Wenming Shao, Zengxi Yao, Yabin Jiang* \\ Department Emergency, The First Affiliated Hospital of Jinan University, Guangzhou, China \\ Email address: \\ abinJiang@163.com (Yabin Jiang) \\ ${ }^{*}$ Corresponding author \\ To cite this article: \\ Wenming Shao, Zengxi Yao, Yabin Jiang. The Significance of Platelet Count in Short-Term Prognosis of Type B Acute Aortic Dissection \\ Patients. International Journal of Biomedical Science and Engineering. Vol. 9, No. 1, 2021, pp. 6-10. doi: 10.11648/j.ijbse.20210901.12
}

Received: December 23, 2020; Accepted: January 7, 2021; Published: January 25, 2021

\begin{abstract}
Background: The lower number of platelet (PLT) has been found to be a risk factor in patients with type A acute aortic dissection (AAD) In admission. However prognostic implications of the PLT count in the type B AAD patients has not yet been elucidated. Methods: We consecutively enrolled 81 patients which confirmed with type B. Patients were divided into survival group and death group and PLT count were measured on admission. Univariate analysis and multiple logistic regression analysis were used to identify the predictors of in-hospital mortality. Results: Compared with the survival group, the death group PLT count was significant lower $\left(172.07 \pm 57.38 \times 10^{9} / \mathrm{L}\right.$ vs. $\left.227.13 \pm 75.97 \times 10^{9} / \mathrm{L}, \mathrm{P}<0.05\right)$. The results showed PLT count (HR: $0.993,95 \%$ CI: $0.987-0.997, \mathrm{P}=0.043$ ), the area under the ROC curve of PLT count was 0.717 , the best cut off was $179.5 \times 10^{9} / \mathrm{L}$, the sensitivity was $72.5 \%$, the specificity was $63.3 \%, \mathrm{P}=0.001$; Log Rang test results showed that there was a statistically significant difference in cumulative survival between the high PLT count group $\left(>179.5 \times 10^{9} / \mathrm{L}\right)$ and the low PLT count group $\left(<179.5 \times 10^{9} / \mathrm{L}\right)$ $(\mathrm{P}=0.001)$. Conclusions: Low PLT on admission count is one of the specific dead risk factors for type B AAD in-hospital patients.
\end{abstract}

Keywords: Platelet Count, Acute Aortic Dissection, Stanford Type B

\section{Introduction}

Acute aortic syndrome (AAS) is a group of diseases with similar clinical symptoms. Eighty-five percent to $95 \%$ of AAS belongs to AAD [1]. AAD is a cardiovascular disease with high morbidity and mortality. About $20 \%$ patients with aortic dissection died before visiting hospital, and the mortality rate was as high as $30 \%$ in in-hospital patients [2]. It is serious threat to human health and safety, and is a disastrous disease with an incidence of about 3/100,000 [3].

Previous studies have reported some predictors of in-hospital mortality of $\mathrm{AAD}$, including type, $\mathrm{D}$-dimer and $\mathrm{C}$ reactive protein [4-6]. Some studies reported the predictors of in-hospital mortality of type A AAD, including age $>$ or $=70$ years, abrupt onset of chest pain, hypotension/shock/tamponade, kidney failure, pulse deficit, abnormal ECG, aortic diameters $>60 \mathrm{~mm}$ [7-9]. Toru Suzuki et al. enrolled 384 type B Patients and identified the predictors of in-hospital mortality, which including absence of chest/back pain on presentation, hypotension/shock, and branch vessel involvement [10]. According to the report [11], hypertension, Marfan syndrome, anterior chest pain, abdominal pain, migrating pain, arch vessel involvement, D-dimer, and $\mathrm{C}$ reactive protein are associated with death of AAD patient in-hospital in China.

During AAD occur, severe coagulation and hemostasis disorders occur in the body, and platelets are involved in the activation of coagulation system factors. In addition, previous studies have reported that low PLT counts at admission may serve as a short-term prognostic risk factor of type A [12]. Herein, we hypothesized that PLT count is also a predicting prognostic factor at admission in type B patients. To our knowledge, this prediction has not been studied.

\section{Methods}

\subsection{Study Population}

In this monocentric retrospective study, 81 patients established initial diagnosis type B were enrolled at Emergency Department of The First Affiliated Hospital of Jinan University from January 2010 to December 2017. These patients were treated with conservative medical treatment, and divided into 
two groups: the deceased group ( $n=31$, consisting of patients who died during hospitalization) and the survival group $(n=50)$. The demographic data, physical examination data, and venous blood samples of patients on admission were collected and analyzed. This study was approved by the medical ethics committee of First Affiliated Hospital of Jinan University.

At the admission, We collected the data 1) First-episode patients, were with chest pain, or chest tightness, back tear-like pain and other clinical symptoms, directly aorta signs (Tear intima and false lumens), or blood biomarkers suggesting suspected AAD; 2) imaging (such as CT, MRI, TTE) diagnosis type B; 3) the completed clinical baseline data was required for this study.

\subsection{Exclusion Criteria}

1) Patient was diagnosed with aortic dissection before admission; 2) Pregnant women was with one of following disorders, tumor, thrombosis, trauma, or blood disorders; 3 ) Patient has chronic inflammatory disease; 4) Patient has not been diagnosed with aortic dissection by imaging; 5) The clinical baseline data of patient for this study is missing.

\subsection{Laboratory Analyses}

Venous blood of patient who was diagnosed AAD at first time was draw and analyzed at emergency department. The components of blood, biochemical, D-dimer and its concentration were determined with immunonephelometry.

\subsection{Endpoint}

In 40 days period of hospitalization, the time of patient death is as end point, and patient self-abandoned treatment is also as end point.

\subsection{Statistical Analysis}

Continuous variables are expressed as mean \pm standard deviation $(\mathrm{X} \pm \mathrm{S})$ and categorical variables are expressed as percentage (\%). For the continuous variable group comparison, an independent sample t-test was used and the Chi-square test was used to compare the categorical variable groups. Univariate Cox regression analysis was used to select the $\mathrm{p}<0.1$ index and included in the multivariate Cox regression analysis. The $\mathrm{p}<0.05$ index was selected by brushing. PLT count was analyzed using the receiver operating characteristic curve (ROC) for type B acute aortic dissection patients in the hospital. Prognosis value, the best cut-off value was obtained; then the best cutoff value of PLT count was divided into high and low groups. Kaplan-Meier survival analysis method was used to determine if there were differences in the survival rate of two different PLT count levels in-hospital.

\section{Result}

\subsection{Baseline Characteristics of Study Population}

The patients were divided into survival group and death group according to the occurrence of death in-hospital. 51 patients in survival groups, 41 males (80.4\%), and 10 females (19.6\%); 30 patients in death group, 22 male (73.3\%), and 8 female (26.7\%). The patients with hypertension were the most common in this study. There were 29 patients (56.9\%) in the survival group, 24 patients $(80 \%)$ in the death group. The hypertension and smoking history were significantly different between the two groups $(\mathrm{P}<0.05)$. However, the gender, age, diabetes, coronary heart disease, polycystic kidney disease, Marfan syndrome, arteritis, and drinking history were not statistically significant difference between the two groups (Table 1).

Table 1. Baseline clinical characteristics of patients.

\begin{tabular}{|c|c|c|c|}
\hline Variable & Survival $(n=51)$ & Death $(n=30)$ & $\mathbf{P}$ \\
\hline \multicolumn{4}{|l|}{ Demographics } \\
\hline Men & $41(80.4 \%)$ & $22(73.3 \%)$ & 0.461 \\
\hline Age (years) & $53.8 \pm 15.8$ & $59.7 \pm 11.0$ & 0.079 \\
\hline$>70$ years & $6(11.8 \%)$ & $6(20.0 \%)$ & 0.494 \\
\hline Hypertension & $29(56.9 \%)$ & $24(80.0 \%)$ & $0.034^{*}$ \\
\hline Diabetes mellitus & $7(13.7 \%)$ & $5(16.7)$ & 0.971 \\
\hline Coronary heart disease & $2(3.9 \%)$ & $4(13.3)$ & 0.262 \\
\hline Holycystic kidney disease & $5(9.8 \%)$ & $3(10.0 \%)$ & 1.000 \\
\hline Marfan syndrome & $1(2.0 \%)$ & $2(6.7 \%)$ & 0.636 \\
\hline Arteritis & $3(5.9 \%)$ & $6(20.0 \%)$ & 0.113 \\
\hline Smoking & $14(27.5 \%)$ & $19(57.6 \%)$ & $0.002^{*}$ \\
\hline Drinking & $13(25.5 \%)$ & $13(43.3 \%)$ & 0.097 \\
\hline \multicolumn{4}{|l|}{ At admission } \\
\hline $\mathrm{SBP}(\mathrm{mmHg})$ & $164.2 \pm 35.6$ & $129.8 \pm 40.5$ & $<0.001^{*}$ \\
\hline $\mathrm{DBP}(\mathrm{mmHg})$ & $92.5 \pm 26.0$ & $74.2 \pm 20.5$ & $0.001^{*}$ \\
\hline $\mathrm{HR}$ (bpm) & $80.0 \pm 13.5$ & $86.8 \pm 16.1$ & $0.042^{*}$ \\
\hline \multicolumn{4}{|l|}{ Laboratory parameters } \\
\hline $\mathrm{WBC}\left(10^{9} / \mathrm{L}\right)$ & $9.35 \pm 2.17$ & $12.15 \pm 3.08$ & $<0.001^{*}$ \\
\hline $\mathrm{N}\left(10^{9} / \mathrm{L}\right)$ & $8.87 \pm 3.99$ & $10.35 \pm 3.33$ & 0.091 \\
\hline $\mathrm{L}\left(10^{9} / \mathrm{L}\right)$ & $1.14 \pm 0.43$ & $0.89 \pm 0.30$ & 0.07 \\
\hline NLR & $7.83 \pm 2.25$ & $11.78 \pm 1.64$ & $<0.001^{*}$ \\
\hline $\operatorname{PLT}\left(10^{9} / \mathrm{L}\right)$ & $227.13 \pm 75.97$ & $172.07 \pm 57.38$ & $0.001^{*}$ \\
\hline MPV (fl) & $9.86 \pm 1.21$ & $10.16 \pm 1.13$ & 0.269 \\
\hline PDW (fl) & $13.40 \pm 2.725$ & $13.87 \pm 2.50$ & $0.045^{*}$ \\
\hline MPV/PLT & $0.05 \pm 0.018$ & $0.08 \pm 0.07$ & $0.004^{*}$ \\
\hline $\mathrm{TC}(\mathrm{mmol} / \mathrm{L})$ & $4.42 \pm 0.88$ & $4.09 \pm 0.70$ & 0.087 \\
\hline TG (mmol/L) & $1.62 \pm 1.13$ & $1.21 \pm 0.51$ & 0.065 \\
\hline LDC-C (mmol/L) & $2.67 \pm 0.83$ & $2.35 \pm 0.54$ & 0.06 \\
\hline HDL-C (mmol/L) & $1.02 \pm 0.27$ & $1.14 \pm 0.29$ & 0.065 \\
\hline CREA (umol/L) & $119.3 \pm 87.5$ & $97.9 \pm 31.2$ & 0.203 \\
\hline URIC (mmol/L) & $375.0 \pm 155.0$ & $429.0 \pm 93.3$ & 0.088 \\
\hline Cys-C (mg/L) & $1.49 \pm 0.88$ & $1.55 \pm 0.55$ & 0.724 \\
\hline $\operatorname{GFR}\left(\mathrm{ml} / \mathrm{min} 1.73 \mathrm{~m}^{2}\right)$ & $83.21 \pm 40.32$ & $80.01 \pm 31.05$ & 0.709 \\
\hline $\mathrm{DD}(\mathrm{ng} / \mathrm{L})$ & $8.03 \pm 1.16$ & $9.31 \pm 0.41$ & $<0.001^{*}$ \\
\hline eGFR (\%) & $35(68.6 \%)$ & $18(60.0 \%)$ & 0.430 \\
\hline Hospital stay (d) & $13.2 \pm 5.9$ & $2.1 \pm 1.0$ & $<0.001^{*}$ \\
\hline$\beta$-blocker & 47 & 25 & 0.393 \\
\hline $\mathrm{CCB}$ & 43 & 21 & 0.127 \\
\hline Isosorbide Dinitrate & 29 & 12 & 0.143 \\
\hline Sodium nitroprusside & 12 & 7 & 0.984 \\
\hline
\end{tabular}

"Statistically significant difference, $\mathrm{P}<0.05$; Mean values (standard deviation) and percent value represented for continuous and categorical variables, respectively. $\mathrm{AD}$ - aortic dissection; $\mathrm{AAD}$ - acute Aortic dissection; PLT - platelet count; $\mathrm{N}$ - neutrophil count; L — lymphocyte count; PDW platelet distribution width; MPV/PLT - mean platelet volume to platelet count ratio; SBP - systolic blood pressure; DBP — diastolic blood pressure; NLR - neutrophil to lymphocyte ratio; HR - heart rate; DD - D-dimer; WBC — white blood cell count; TC — total cholesterol; TG - triglycerides; LDL-C — low-density lipoprotein; HDL-C — high-density lipoprotein; UA — uric Acid; $\mathrm{Cr}$ - creatinine; eGFR - estimated glomerular filtration rate; Cys-c - cystatinc; $\mathrm{CCB}$ - calcium channel blockers; Ln-Dimer is the natural logarithm of D-dimer; CI - confidence interval; HR — hazard ratio. 


\subsection{Analysis of Type B Mortality Risk Factors In-hospital}

Cox regression analysis

Table 2. Univariate logistic regression analysis predictors of all-cause mortality at the end of follow-up.

\begin{tabular}{|c|c|c|}
\hline Variables & HR $(95 \%$ CI $)$ & $\mathbf{p}$ \\
\hline Men (\%) & $1.387(0.613-3.097)$ & 0.438 \\
\hline Age (years) & $1.019(0.995-1.043)$ & 0.128 \\
\hline$>70$ years & $0.683(0.279-1.671)$ & 0.403 \\
\hline Hypertension & $2.269(0.927-5.557)$ & 0.073 \\
\hline Diabetes mellitus & $0.833(0.319-2.17)$ & 0.710 \\
\hline Coronary heart disease & $0.404(0.141-1.162)$ & 0.093 \\
\hline Holycystic kidney disease & $1.015(0.308-3.347)$ & 0.98 \\
\hline Marfan syndrome & $0.582(0.138-2.450)$ & 0.582 \\
\hline Arteritis & $0.473(0.193-1.159)$ & 0.101 \\
\hline Smoking & $0.313(0.148-0.660)$ & $0.002^{*}$ \\
\hline Drinking & $0.549(0.266-1.131)$ & 0.104 \\
\hline $\mathrm{SBP}(\mathrm{mmHg})$ & $0.980(0.969-0.990)$ & $0.000^{*}$ \\
\hline DBP (mmHg) & $0.975(0.959-0.991)$ & $0.003^{*}$ \\
\hline HR (bpm) & $1.029(1.003-1.057)$ & $0.032^{*}$ \\
\hline WBC $\left(10^{9} / \mathrm{L}\right)$ & $1.091(0.988-1.204)$ & 0.084 \\
\hline $\mathrm{N}\left(10^{9} / \mathrm{L}\right)$ & $1.069(0.980-1.165)$ & 0.131 \\
\hline $\mathrm{L}\left(10^{9} / \mathrm{L}\right)$ & $0.276(0.096-0.796)$ & $0.017^{*}$ \\
\hline $\mathrm{M}\left(10^{9} / \mathrm{L}\right)$ & $0.250(0.051-1.217)$ & 0.086 \\
\hline NLR & $1.517(1.331-1.756)$ & $0.000^{*}$ \\
\hline $\operatorname{PLT}\left(10^{9} / \mathrm{L}\right)$ & $0.990(0.983-0.996)$ & $0.002^{*}$ \\
\hline MPV (fl) & $1.234(0.903-1.678)$ & 0.188 \\
\hline PDW (fl) & $1.038(0.910-1.185)$ & 0.577 \\
\hline $\mathrm{TC}(\mathrm{mmol} / \mathrm{L})$ & $0.706(0.455-1.094)$ & 0.120 \\
\hline $\mathrm{TG}(\mathrm{mmol} / \mathrm{L})$ & $0.627(0.35-0.120)$ & 0.115 \\
\hline LDC-C (mmol/L) & $0.567(0.401-1.076)$ & 0.095 \\
\hline HDL-C (mmol/L) & $2.917(0.867-9.801)$ & 0.084 \\
\hline $\mathrm{Cr}(\mathrm{umol} / \mathrm{L})$ & $0.996(0.990-1.003)$ & 0.285 \\
\hline $\mathrm{UA}(\mathrm{mmol} / \mathrm{L})$ & $1.001(0.999-1.003)$ & 0.149 \\
\hline Cys-C (mg/L) & $1.074(0.702-1.644)$ & 0.743 \\
\hline eGFR $\left(\mathrm{ml} / \mathrm{min} 1.73 \mathrm{~m}^{2}\right)$ & $0.998(0.988-1.007)$ & 0.636 \\
\hline Ln-D-dimer (ng/L) & $2.863(1.730-4.737)$ & $0.000^{*}$ \\
\hline
\end{tabular}

"Statistically significant difference, $\mathrm{P}<0.05$; CI — confidence interval; HR hazard ratio; others abbreviations as in Table 1

Table 3. Multivariate logistic regression analysis predictors of all-cause mortality at the end of follow-up.

\begin{tabular}{lll}
\hline Variables & HR (95\% CI) & p \\
\hline Smoking & - & 1.681 \\
SBP $(\mathrm{mmHg})$ & $0.987(0.977-0.997)$ & $0.010^{*}$ \\
DBP $(\mathrm{mmHg})$ & - & 0.096 \\
HR $(\mathrm{bpm})$ & - & 0.744 \\
L $\left(10^{9} / \mathrm{L}\right)$ & - & 0.093 \\
NLR & $1.418(1.262-1.739)$ & $<0.001^{*}$ \\
PLT $\left(10^{9} / \mathrm{L}\right)$ & $0.993(0.987-0.997)$ & $0.043^{*}$ \\
Ln-D-dimer (ng/L) & - & 1.884 \\
\hline
\end{tabular}

*Statistically significant difference, $\mathrm{P}<0.05$; SBP, NLR, PLT were associated with increased risk of all-cause mortality, death from multivariate Cox regression analysis by forward likelihood ratio method. Variables for $\mathrm{p}<0.05$ on univariate analysis were shown and included in the multivariable model. $\mathrm{CI}$ - confidence interval; HR - hazard ratio; others abbreviations as in Table 1 .

According to endpoint event, patients of Type B AAD were divided into survival group and death group. Detailed information on predictors of in-hospital death by using Cox regression analysis is listed (Table 2 and Table 3). Univariate
COX Regression Analysis: History of hypertension at admission, coronary heart disease, smoking, systolic blood pressure, diastolic blood pressure, heart rate, white blood cell count, lymphocyte count, neutrophil to lymphocyte ratio (NLR), PLT count, D-dimer, and high density lipoprotein. Multifactor COX regression analysis: low Density lipoprotein was $\mathrm{P}<0.1$; and others were $\mathrm{p}<0.1$; $\mathrm{PLT}(\mathrm{HR}=0.993$, $\mathrm{P}=0.043)$ NLR $(H R=1.418, \mathrm{P}<0.001) \mathrm{SBP}(\mathrm{HR}=0.987, \mathrm{P}<0.001)$.

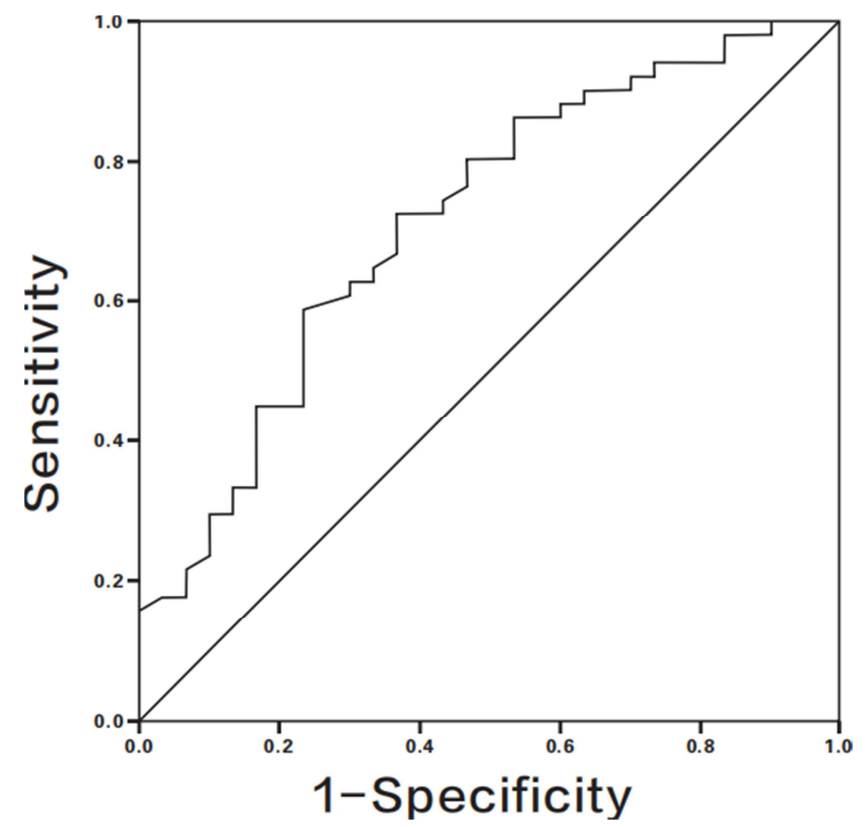

Figure 1. Legend. Receiver operating characteristic curve of platelet count for predicting in-hospital mortality in patients with type $B$ acute aortic dissection.

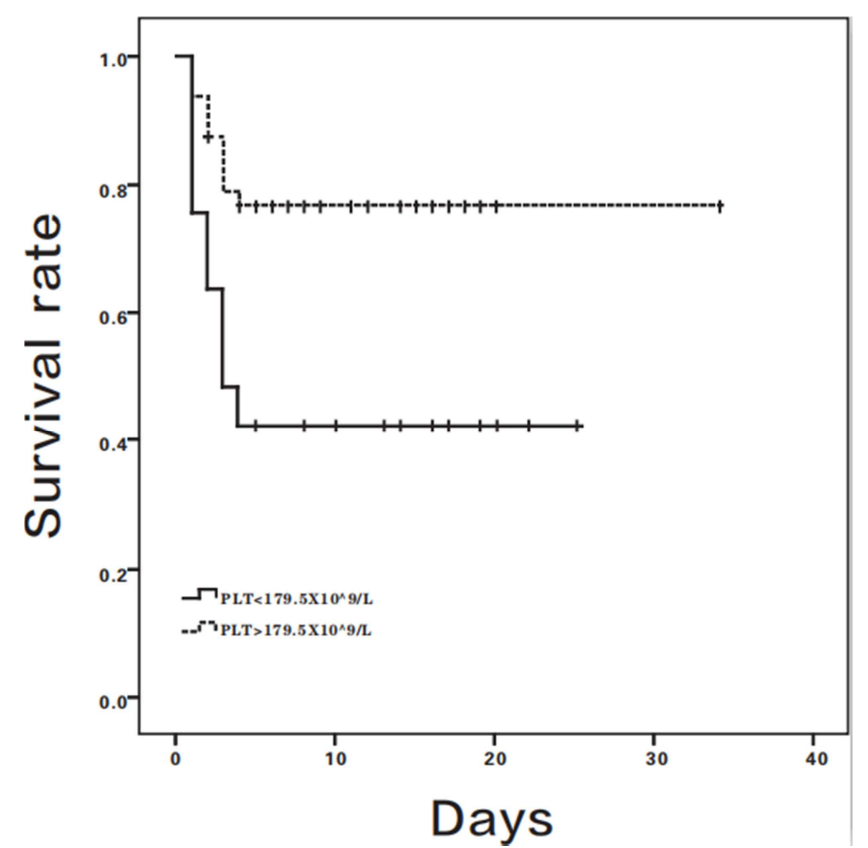

Figure 2. Legend. Kaplan-Meier survival curves comparing in-hospital mortality between patients with platelet counts $>179.5 \times 109 / \mathrm{L}$ and $\leq \times 109 / \mathrm{L}$ (log rank $p=0.001)$. 


\subsection{Prognostic Significance of PLT Count}

The possibility of PLT count to predict for prognosis of AAD was evaluated by area under the ROC curve (AUC). The AUC for PLT was 0.717 (95\% confidence interval [CI] $0.601-0.833, \mathrm{P}=0.001$ ) (figure 1), when Youden index $=0.39$, the optimal cutoff value of $179.5 \times 10^{9} / \mathrm{L}$, with the sensitivity of $72.5 \%$, specificity of $63.3 \%$. The survival in patients curves with PLT counts $\leq 179.5 \times 10^{9} / \mathrm{L}$ and $>179.5 \times 10^{9} / \mathrm{L}$ were constructed, and the cumulative in-hospital mortality was significant higher in patients with platelet counts $\leq 179.5 \times$ $10^{9} / \mathrm{L}$ than those with platelet counts $179.5 \times 10^{9} / \mathrm{L}(\log$ rank=0.001) (figure 2).

\section{Discussion}

The present study has shown that the PLT counts were significantly lower in type B patients of deceased group, as compared to that in the patients of survival group $\left(172.07 \pm 57.38 \times 10^{9} / \mathrm{L}\right.$ vs. $\left.227.13 \pm 75.97 \times 10^{9} / \mathrm{L}, \mathrm{P}<0.05\right)$. With the best cutoff value of $179.5 \times 10^{9} / \mathrm{L}$, patients with lower platelet count $\leq 179.5 \times 10^{9} / \mathrm{L}$ as compared to patients with higher platelet count $>179.5 \times 10^{9} / \mathrm{L}$ at admission, has significantly increased in-hospital mortality. Low PLT count at admission was independently associated with in-hospital death of type B patients $(\mathrm{HR}=0.993$, $\mathrm{P}<0.05)$, will increase mortality and be negatively correlated with type B mortality.

When the aortic dissection occurs, the vascular endothelial collagen tissue is exposed, the PLT is induced to initiate hemostasis and aggregate, various factors involved in coagulation function are released, and formed blood clot finally. At the same time, the body is in a highly activated state, which activates the coagulation and fibrinolysis system of the body. The activated PLT in the false lumens form a thrombus, resulting in a drop in the PLT count in the body. Chaoyi Qin et al [13] proved that the PLT count $(\mathrm{K} / \mathrm{ul})$ in aortic dissection is lower than chronic aortic aneurysm and healthy people. This change of PLT count may be related to extent of dissection, and is consistent with the findings of earlier study by Tanaka et al. [14]. Huang Bi et al. [12] reported that in type A patients, the platelet count in the survival group was higher than that in the deceased group. The study also showed that low platelet count at admission may be an increased risk of in-hospital death in type A patients after adjustment of baseline clinical characteristics and related biochemical variables in all type A patients. Fulvio Morello et al. [15] enrolled 271 patients diagnosed with AAS, 1210 patients suspected aortic syndrome, and 1006 patients classified at low probability which indicated that PLT count $<200 \times 10^{3} / \mu \mathrm{L}$ was an independent predictor of risk factors of aortic syndrome. For the distribution width in type B patients, Morello F et al. [14] indicated that AAD was higher as compared with chronic aortic aneurysms and healthy controls (PDW (fl) $(17(16.7,17.4)$ vs. 16.6 (16.2, $17.1)$ vs. $16.6(16.4,17), \mathrm{P}<0.001$ and $\mathrm{P}<0.05)$. In present study, we did not find the significant differences in the platelet-related parameters (platelet distribution width and mean platelet volume) between the survival group and the deceased group. This result is consistent with the previous report [12]. In addition, our study showed that neutrophil to lymphocyte ratio (NLR) was associated with in-hospital mortality of type $\mathrm{B}$ patients $(\mathrm{HR}=1.418, \mathrm{P}<0.05)$. Onuk $\mathrm{T}$ et al. [17] enrolled

$200 \mathrm{AD}$ patients, 76 ascending aortic aneurysms patients, and 92 common patients, and they were found that the NLR was higher in AD patients than that in others patients. They also found that at admission, the NLM was significant higher in decease group as compared with survival group. The other study [18] showed that NLR of aortic dissection patients was significantly higher than non-aortic dissection patients. The NLR is a fast, simple, economic, accurate and objective blood biomarkers for AAD, and it is worth recommending and applying widely in clinic. Furthermore, Present study showed that systolic blood pressure (SBP) was significant lower in deceased group than that in the survivor group $(129.8 \pm 40.5$ vs. $164.2 \pm 35.6, \mathrm{P}<0.05)$. After adjusting for conventional clinical factors, it was found that the SBP of type $\mathrm{B}$ patients at admission was the predictive factors for short-term prognosis $(\mathrm{HR}=0.987, \mathrm{P}=0.01)$. Low blood pressure at admission may be related to aortic dissection complications (such as vessel rupture, pericardial pleural effusion, involvement of vital organs, etc.) happened before the patient visiting. Previous studies $[19,20]$ have proved that hypotension and shock are the specific risk factors for preoperative death in type A patients. When AAD occurred, the body is in a state of high stress, the blood pressure is increasing to ensure the perfusion of vital tissues, as a normal response of the body. However, the increasing blood pressure may be increasing the extent of tearing aortic dissection or even aortic rupture. AAD patients at admission, SBP may distribute an inverted "U", from which we can find a cutoff to achieve balance the pros and cons.

\section{Conclusions}

In conclusion, low PLT count of type B patients at admission was one of the risk factors associated with in-hospital death. It may be one of the risk stratification indicators for predicting in-hospital prognosis.

\section{Conflicts of Interest}

All the authors do not have any possible conflicts of interest.

\section{Acknowledgements}

We thank Jinan University that provides a broad resource to study, and would like to thank the patients for their trust and support. The authors are thankful to Hansheng Lin (Department of Medical Statistics, Jinan University School of Medicine) for providing advice regarding the statistical analysis. 


\section{References}

[1] Morris JH, Mix D. Cameron SJ Acute Aortic Syndromes: Update in Current Medical Management. Curr Treat Options Cardiovasc Med. 2017; 19 (4): 29.

[2] Masuda Y, Yamada Z, Morooka N, Watanabe S, Inagaki Y. Prognosis of patients with medically treated aortic dissections. Circulation. 1991; 84 (5 Suppl): 7-13.

[3] McCullough JN, Zhang N, Reich DL, Juvonen TS, Klein JJ, Spielvogel D et al. Cerebral metabolic suppression during hypothermic circulatory arrest in humans. Ann Thorac Surg. 1999; 67 (6): 1895-9; discussion 1919-21.

[4] Tsai TT, Fattori R, Trimarchi S, TsIsselbacher E, Myrmel T, Evangelista A, et al. Long-term survival in patients presenting with type B acute aortic dissection: insights from the International Registry of Acute Aortic Dissection. Circulation. 2006; 114 (21): 2226-31.

[5] Tsai TT, Evangelista A, Nienaber CA, Trimarchi S, Sechtem U, Fattori R, et al. Long-term survival in patients presenting with type A acute aortic dissection: insights from the International Registry of Acute Aortic Dissection (IRAD). Circulation. 2006; 114 (1 Suppl): I350-6.

[6] Wen D, Du X, Dong JZ, Zhou XL, Ma CS. Value of D-dimer and $C$ reactive protein in predicting inhospital death in acute aortic dissection. Heart. 2013; 99 (16): 1192-7.

[7] Mehta RH, Suzuki T, Hagan PG, Bossone E, Gilon D, Llovet A, et al. Predicting death in patients with acute type a aortic dissection. Circulation. 2002; 105 (2): 200-6.

[8] Mehta RH, O'Gara PT, Bossone E, Nienaber CA, Myrmel T, Cooper JV, et al. Acute type A aortic dissection in the elderly: clinical characteristics, management, and outcomes in the current era. J Am Coll Cardiol. 2002; 40 (4): 685-92.

[9] Sütsch G, Jenni R, von SL, Turina M, et al. Predictability of aortic dissection as a function of aortic diameter. Eur Heart $\mathrm{J}$. 1991; 12 (12): 1247-56.

[10] Suzuki T, Mehta RH, Ince H, Nagai R, Sakomura Y, Weber F, et al. Clinical profiles and outcomes of acute type $\mathrm{B}$ aortic dissection in the current era: lessons from the International Registry of Aortic Dissection (IRAD) [J]. Circulation, 2003; 108 Suppl 1: II312-7.
[11] Li Y, Yang N, Duan W, Liu S, Liu S, Yu S, Yi D. Acute aortic dissection in China. Am J Cardiol. 2012; 110 (7): 1056-61.

[12] Huang B, Tian L, Fan X, Zhu J, Liang Y, Yang Y. Low admission platelet counts predicts increased risk of in-hospital mortality in patients with type A acute aortic dissection. Int J Cardiol. 2014; 172 (3): e484-6.

[13] Qin, C., Zhang, H., Gu, J. et al. Dynamic monitoring of platelet activation and its role in post-dissection inflammation in a canine model of acute type A aortic dissection. J Cardiothorac Surg. 2016; 86: 11 .

[14] Tanaka M, Kawahito K, Adachi H, Ino T. Platelet dysfunction in acute type A aortic dissection evaluated by the laser light-scattering method. J Thorac Cardiovasc Surg. 2003; 126 (3): $837-41$.

[15] Morello F, Cavalot G, Giachino F, Tizzani M, Nazerian P, Carbone F, et al. White blood cell and platelet count as adjuncts to standard clinical evaluation for risk assessment in patients at low probability of acute aortic syndrome. Eur Heart J Acute Cardiovasc Care. 2017; 6 (5): 389-395.

[16] Sbarouni E, Georgiadou P, Analitis A, Voudris V. Significant changes in platelet count, volume and size in acute aortic dissection. Int J Cardiol. 2013; 168 (4): 4349-50.

[17] Onuk T, Güngör B, Karataş B, Ipek G, Akyüz S, Ozcan KS, et al. Increased Neutrophil to Lymphocyte Ratio is Associated with In-Hospital Mortality in Patients with Aortic Dissection. Clin Lab. 2015; 61 (9): 1275-82.

[18] Oz K, Iyigun T, Karaman Z, Çelik Ö, Akbay E, Akınc O, et al. Prognostic Value of Neutrophil to Lymphocyte Ratio and Risk Factors for Mortality in Patients with Stanford Type A Aortic Dissection. Heart Surg Forum. 2017; 20 (3): E119-E123.

[19] Spirito R, Pompilio G, Alamanni F, Agrifoglio M, Dainese L, Parolari A, et al. A preoperative index of mortality for patients undergoing surgery of type A aortic dissection. J Cardiovasc Surg (Torino). 2001; 42 (4): 517-24.

[20] Rampoldi V, Trimarchi S, Eagle KA, Nienaber CA, Oh JK, Bossone E, et al. Simple risk models to predict surgical mortality in acute type A aortic dissection: the International Registry of Acute Aortic Dissection score. Ann Thorac Surg. 2007; 83 (1): 55-61. 